\title{
High quality bee products are important to agriculture: why, and what needs to be done
}

\author{
Peter G Kevan*, Dan Eisikowitch, Wanja Kinuthia, Peter Martin, E C Mussen, Uma Partap, \\ O R Taylor, Vernon G Thomas, R W Thorp, Carlos H Vergara and Kimberly Winter
}

Received 24 April 2006, accepted subject to revision 3 I May 2006, accepted for publication 2I November 2006.

* Corresponding author: Email: pkevan@uoguelph.ca

\section{Introduction}

It is well recognized that honeybees are major players in agricultural productivity through their roles in crop pollination, and are economically valuable for hive products (mostly honey) but the indirect link between honey quality and agricultural productivity is seldom voiced.

Honey is a valued and revered part of human diets. It is not just a sweetener, but also has special places in culture, religion, and medicine. The value of honey rests in its reputation for purity and that value is of paramount importance to the beekeeping industry and associated value added enterprises in packing, marketing, advertising, wholesale and retail sales. If the reputation of honey as a healthy component of human diet is eroded, then the beekeeping industry becomes jeopardized. Contamination of honey by pesticide (or antibiotic) residues from applications to crops or directly to colonies of honeybees, or adulteration of honey by unscrupulous commercial interests, detracts from honey's repute. Similarly, concerns for contamination with GMO (Genetically Modified Organisms) in the form of pollen are frequently raised (see literature review on the web; reference below). One would expect the market for honey to be adversely affected if honey's reputation were eroded. Honey regarded as inferior in quality commands lower prices in the international market. If the market for honey were to decline, and the price to drop, there would be serious consequences to crop production in general resulting from deterioration of beekeeping as an agricultural endeavour and the consequent abandoning of the activity by beekeepers.

Having spelled out the generalities in the interconnectedness between honey quality and agricultural productivity, what are the specifics within the area of pollination that relate to government and industry policies on honey purity? This report provides a short summary of the facets of pollination and beekeeping that apply, with recommendations of the stands that need to be taken to protect and assure honey quality for the sake of adequate pollinator forces for agriculture.

\section{Valuation of pollination services}

There have been several valuations of honeybee pollination to crop yields: USA $\$ 9.3$ billion in 1987, $\$ 14.6$ billion in 2000 (Morse and Calderone 2000), Canada $\$ 0.44$ billion in 1990, $\$ 0.78$ billion in 1998 (www.honeycouncil.ca), European Union $\$ 4.25$ billion (Borneck and Merle 1989), United Kingdom 1200 million (Carreck and Williams 1998), Australia \$0.6-1.2 billion in 1989 , $\$ 2.4$ billion in 200 I (Gordon and Davis 2003). The various analysts take various factors into consideration, so the question of the value of honeybees in pollination is complex (Southwick and Southwick 1992; Kevan and Phillips 200 I; Rucker et al. 2003; NRC 2006).

Buchmann and Nabhan (1996) state that the comparison of (potential) yield lost if pollinators (including honeybees) were absent with yields obtained in their presence provides a figure of value. Factoring out the contribution of honeybees becomes difficult in that honeybees could be replaced with other pollinators with or without management, as Southwick and Southwick (1992) point out. The estimates provided use the gross values of crops weighted by the estimated proportion of crop attributable to honeybee pollination. That may vary from complete dependence on honeybee pollination to complete independence. Further, calculations involve not only the immediate value of crop sold on the market, but also value added by further use. Thus, the value of forage plant seed production becomes reflected in additional livestock production, potential and realized. Despite the inconsistencies between various valuation methods, and no matter how the calculations are made by incorporating various factors, the value of honeybees to agricultural production is huge. In general and perhaps as a 'rule of thumb', a figure of 7-10 times the value of hive products can be attributed to pollination. Although those valuations are useful, they are simplistic and do not take into account issues of elasticity 
of prices under varying conditions of supply and demand (see Economic consequences below).

Beekeepers' revenues from providing pollination services also need to be incorporated into the figures above. The cost:benefit ratios that reflect the growers' returns on investment into pollination services are variable, ranging from 1:5 to 1:192 for some Canadian figures, depending on crop, yearly vagaries in yield, and regional differences (Kevan and Phillips 200 I). In general, it is safe to state that growers benefit hugely from pollination services provided by beekeepers, and that pollination services are a small component of growers' costs of operation.

The contribution of the honeybees (Apis spp.) to the pollination of wild plants is particularly great in regions where they are native (i.e. Europe, Asia, and Africa) but the economic value of these bees to pollination has never been evaluated. Probably, their ecological value cannot be considered in terms by proximate measures in monetary terms.

\section{Recommendations}

In general, the value of honeybees and beekeeping to agricultural production is under-appreciated and probably hugely undervalued. To encourage professional and ethical beekeeping practices the following recommendations apply.

The value of honeybees and beekeeping to agricultural productivity needs to be demonstrated by more examples from other parts of the world.

The cost: benefit ratio for growers using honeybee pollination services needs to be worked out on a crop by crop, region by region, basis and averaged over several years so that beekeepers can obtain a fair price for their services.

The value of honeybees and beekeeping to agricultural productivity needs to be assessed regularly (perhaps once every five years) in all countries where beekeeping and pure honey production is important.

The value of honeybees and beekeeping to agricultural productivity needs to be assessed by some uniform methodology that incorporates all relevant factors and that prescribed methodology should be decided upon by an international body.

The value of honeybees and beekeeping to agricultural productivity needs to be publicly stated in a recurrent manner, as to make this information part of the day-to-day life of the public.

Honey International Packers Association (HIPA) supports these recommendations and is encouraging of the establishment of an arm of Apimondia devoted to assessing the value of honeybees and beekeeping to agricultural productivity.

\section{Economic consequences of pollinator shortages}

Pollinator shortages are being reported from various parts of the world. The situation is now recognized as sufficiently grave that the Convention on Biological Diversity (Rio Convention) has embraced the problem and the Food and Agricultural Organization of the United Nations has taken on the responsibility for the International Pollinators Initiative (IPI). Other regional initiatives for the protection of pollinators and pollination have arisen in North America (North American Pollinator Protection Campaign), Africa (African Pollinator Initiative), and Brazil, and organizations in Europe and in various countries are being formed.
Although general pollinator faunas, and pollination, are of paramount concern, the honeybee industry is very much involved. Some examples of the consequences of shortages of honeybees for pollination can be found from Asia where in some parts of China, Nepal, and India pesticide applications have caused beekeeping to become problematic so beekeepers try keep their colonies away from crops associated with pesticide applications, and honeybees are absent from where they are needed for pollination. The prime example is for pollination of pome fruits, particularly apples, which is now accomplished artificially (Partap and Partap 2002). The shortage of honeybees for pollination of other crops is being experienced for almond particularly in California, where 1.4 million honeybee colonies were required in 2005. Given the growth in almond cultivated area projected for the next six years, California will require about two million colonies for almond pollination alone by 2012 (Sumner and Boriss 2006); blueberries in Maritime Canada and Maine, cucurbit crops (cucumbers and melons) in various parts of the world (e.g. some years ago in Israel), and so on. There has been no worldwide survey of this problem, but the increasing number of reports indicates a growing problem.

Related to the remarks above are recent findings that crops generally regarded as being independent of insect pollination for maximum yields are showing increased yields when honeybees are added into the production scheme. One such crops is coffee, which is self pollinating and very important to tropical agriculture. Coffee was considered to gain nothing from insect pollinators, but Roubik (2002), studying the effect of pollination by Africanized honeybees on coffee production in Panama, showed that naturalized, non-native honeybees can augment pollination and boost crop yields by over $50 \%$. Some cultivars of soybeans and other oil-seed crops are also prime examples and show that much remains to be learned of the economic importance of honeybee pollination.

Economic analyses of the economic consequences of pollinator shortages have not been attempted very often. As noted above, the valuation of pollinators in crop production cannot be used, except as a starting point, in economic analyses. Kevan and Phillips (200I) and NRC (2006) general analyses point out that pollinator shortages can result only in the increase in food and fibre prices to consumers, especially for goods that originate from honeybee pollinated plants. Unfortunately, there seem to be no examples by which actual rises in commodity prices can be traced to pollinator shortages, even though it is assumed that prices of such commodities as palm oil, alfalfa seed, and other insect pollinated crops reflect the benefits of adequacy of pollination. Rucker et al. (2003) point out that a rise in honey prices by 10\% (encouraging beekeepers to produce honey rather than provide pollination services) would likely cause a much greater (5-fold) increase in pollination service fees than would the increase by $10 \%$ in the production of the pollinated crop. Those considerations do not embrace the cost:benefit ratio for growers needs when using honeybee pollination services (see above), but are based on present supply and demand economics. 


\section{Recommendation}

In general, there is a great need for rigorous economic assessment of honeybees and beekeeping to agricultural production through pollination. A framework from which to demonstrate the importance of pollination in the elasticity of supply and demand of food and fibre would allow for beekeeping to become a greater part of regional, national and international policies in agriculture, trade, and commerce. Such recognition would stimulate professional and ethical beekeeping practices. The following recommendation applies:

A number of signature crops need to be chosen for special consideration for the economics of pollination, with particular reference to pollinator shortages, honeybees and beekeeping. The preliminary approaches by Southwick and Southwick (1992), Kevan and Phillips (200 I) and Rucker et al. (2003) are appropriate first steps. Crops primarily pollinated by honeybees and of international importance should be chosen for study. Apples, coffee, avocado and almond are suggested in the first instance because of the amount of international trade, the variety of production systems in use (including in pollination), and the amount of existing information on their value and dependence on beekeeping for production.

\section{Pesticides applied to crops and pollinator health}

A major problem for beekeepers is that of pesticide poisoning. As long as pesticides continue to be used, there will be adverse consequences to honeybees and beekeeping. Although the problem is well recognized, and the means for reducing honeybee losses caused by pesticides are well known (e.g. Johansen and Mayer 1990), additional considerations need to be introduced in concerns for pollinator health (for residue issues, see below).

Most pesticides carry cautions about their use in the vicinity of honeybees. Tests on honeybees are required for registration of most pesticides, and all insecticides. In some jurisdictions there are laws that prohibit the application of pesticides to blooming crops. In many places there are no such laws. In the places where such laws exist (e.g. Ontario, Canada where it was intended primarily to protect pollinating honeybees in orchards) contentions between growers, applicators, and beekeepers often flare up over the interpretation of the laws. For example, according to some interpretations maize does not bloom (that is simply wrong), presumably because it does not have a showy flower. Thus, insecticide applications to pollen-shedding maize are, in scientific reality, contrary to the law and pose a hazard to maize-pollencollecting honeybees.

There have been problems reported with applications of new generation systemic insecticides as seed treatments, as exemplified by imidacloprid. This insecticide translocates to nectar and pollen where it adversely affects pollinators, e.g. bumblebees on greenhouse tomatoes and perhaps honeybees on field crops through subtle and sublethal effects (see Belzunces et al.

(eds) 200I).

Herbicides are generally not hazardous to honeybees in a direct sense, but their impact on vegetation can be profound. Thus, herbicides used on rights-of-way, field margins, untilled ground, and so on can reduce profoundly the incidence of flowers in a particular area. Not only does that impact the potential for honey harvest in the region, it can, when severe, adversely affect the growth and strength of honeybee colonies.
Beekeepers may be able to remove their bees to more productive locations, but that adds to costs of operation. Perhaps more importantly herbicide applications adversely affect native pollinators, sometimes important for crops, to the extent that honeybees must be employed, moved in and out for the duration of bloom. That increases cost of crop production, and mostly does not contribute to honey production.

\section{Recommendations}

In general, beekeeping is adversely affected by applications of pesticides applied to crops. Although there are various safeguards in place to mitigate those effects, they need to be more definitively formulated than at present. The following recommendations apply:

In the process of registration, companies need to employ more rigorous tests involving honeybees. The present situation with respect to imidacloprid and the so-called 'mad bee disease' is a point in case. For this highly persistent and plant systemic insecticide, the manufacturer has altered its stance to increasing safety. The impetus for that has been pressure from the beekeeping community. Nevertheless, several important questions remain to be answered about the safety of this, and other new, insecticides to honeybees and other pollinators.

Laws are needed to prohibit the application of pesticides (and especially insecticides) to blooming crops (especially those to which honeybees and other pollinators go to forage) in each and every appropriate jurisdiction.

Laws are needed to protect the environment from largely cosmetic applications of herbicides so that nectar and pollen plants can persist.

Special attention is needed to educate growers and land users that pollinators, and particularly honeybees benefit from that presence of plants other than crops, and that the other plants can improve the efficacy of pollination of some crops. On the other hand, some flowering plants may compete with crops for the attentions of pollinating honey bees. Attention needs to be paid to these ecological interactions to determine how best to accommodate the needs of honey production and crop pollination.

\section{Pesticides applied to crops and residues in honey and other bee products}

Apart from the direct threats to honeybees posed by pesticides applied to crops, are the problems associated with pesticide residues contaminating hive products. Thus, chemicals that are variously highly toxic to non-toxic to honeybees can find their way into hives and detract from the quality of hive products. However, relatively low concentrations of pesticides have been found in honey, apparently as a result of a filtering effect of bees (Schur and Wallner 1998). The contamination of honey and other bee products has been recently reviewed by Bogdanov (2006). The contamination levels found rarely exceed the MRL values established for other foods. Indeed, there are very rarely honeyspecific MRL values, so that food control authorities can not take action. The contamination of hive products by pesticides used in general agriculture is generally lower than that caused by those (e.g. acaricides) used in beekeeping (below). Pollen is the bee products, which is mostly endangered by pesticide use (Bogdanov, 2006). 
The points to be made are similar to those under item 3 (above), but include issues to do with non-toxic-to-bees contaminants. The following recommendations apply:

\section{Recommendations}

In the process of registration, companies need to employ more rigorous tests involving hive products and residues

Laws are needed to prohibit the application of any pesticide to blooming crops (especially those to which honeybees and other pollinators go to forage) if that pesticide has the capacity to become residual in hive products and so adversely affect the purity of honey and other hive products.

Special attention is needed to educate growers and land users that beekeepers benefit from that presence of plants other than crops, and that the other plants often produce nectar and pollen that becomes part of the beekeeping industry's offerings to consumers. Thus, purity through lack of pesticide residues needs to be assured for the sake of the reputation of honey and other hive products, and for safety for consumers.

\section{Pesticides and antibiotics applied to protect living colonies}

The major problems that face the honey industry are product purity and absence of residues of pesticides and antibiotics applied to honeybee colonies originally used to promote the health and strength of colonies. The main contaminants coming from beekeeping practices are acaricides (lipophylic synthetic compounds and non-toxic substances such as organic acids and components of essential oils) and antibiotics used for the control of bee brood diseases (mainly tetracyclines, streptomycine, and chloramphenicol). Other substances used in beekeeping play a minor role (e.g. para-dichlorobenzene, used for the control of wax moth, and chemical repellents). Because consumers today expect that honey is a natural product, free of residues, reports in the mass media about antibiotic residues are detrimental for the positive image of honey and should be avoided by any means. Antibiotics and chemical pesticides for controlling the Varroa mite and other pests become residual in hive products, especially bees' wax and honey, so that inspections and testing are routine in many places. Non-toxic natural acaricides, such as thymol and organic acids, used at proper times of the year, do not change the taste of honey and are found at levels below the values accepted by international honey regulations (Bogdanov 2006). The most important problem for honey is its contamination by antibiotics used for the control of bee brood diseases (Bogdanov et al. 2006). Beekeepers all over the world use many types of antibiotics, even though their use is not always necessary. Another big problem is the regular use of acaricides for Varroa control. This leads to a heavy contaminaton of beeswax, and to a lesser degree, also of honey. Some bee diseases can be controlled effectively without the use of chemicals (e.g. American foul brood (Waite et al. 2003; Ohe 2003); Varroa (Imdorf et al. 2003); and both (Spivak and Gilliam 1998)) and strategies of Integrated Pest Management can be used (Kevan 2004).

\section{Recommendations}

In many places, more fastidious testing for chemical residues in hive products, particularly honey, is required to assure consumers' safety and product purity. This is especially important for international trade.

Beekeepers need to be more cognizant of the problems caused by improper use (timing, duration, formulation, and dose) of chemicals in bee hives because of the implications to the industry in general and their peers.

The use of non-toxic natural acaricides needs to be promoted among beekeepers, following proper guidelines for timing formulation and dose.

The beekeeping organizations and the bee research community should assume their responsibility for offering the beekeepers alternative procedures for dealing with bee diseases.

\section{Hive products and GMOs}

A comparatively new concern for the beekeeping and honey industry is the presence of pollen from genetically modified crops (GMOs) in hive products, including bees and honey. Williams (2002a, b) has reviewed the regulatory framework of the EU regarding the GMO for beekeeping and bee products, pointing out consumer interest in food safety, choice, labeling, tracability, and quality. Although a human health issue has not been identified, a number of studies made in Europe and North America have demonstrated pollen from GM soya beans, canola, and other crops can be found in honey (see item A at the end of the references below). The source of some of that pollen is from field grown crops destined for harvest and consumption, another source is from GM crops being grown and pollinated by honeybees for hybrid and pure seed production for use in planting. The presence of GM pollen in hive products is not acceptable under policies of zero-tolerance for GM in the human food chain or in the environment in general, for organic producers, and is an issue for the establishment of guidelines for acceptable levels of GM materials in human food. In some countries such as USA and Canada genetically modified plants are commonly grown, but in the European Union there is wide opposition to the consumption of food containing GMO's. In the European Union the labelling of GMO content in food is compulsory above I \%.

\section{Recommendations}

There is a need for in-depth consideration for the guidelines of GMO's in hive products. Those guidelines need to consider the realities of agriculture in countries with large investments into GM crop production, the expectations of countries importing from those countries, and issues of product labelling. It seems that more fastidious testing for GMO's in hive products, particularly honey, is required to assure consumers' of product purity and quality is met according to their demands. This is especially important for international trade.

Beekeepers need to be more cognizant of the problems caused by GMO materials entering beehives because of the implications to the industry in general and with respect to consumer expectations and demands. 


\section{New uses of honeybees}

Honeybees have been used traditionally for production of hive products, and for pollination. Honeybee management evolves in direct relationship to discoveries in basic bee biology. In the future, some aspects of honeybee management may be quite different from anything we are familiar with today. A symbiosis exists between beekeeping management and beekeeping research so research institutes are well positioned to help beekeepers with their management problems through discoveries in fundamental and applied research that are often the starting points for future commercial applications. Recently, other uses are being explored, notably in the area of biological control of pests on crops. Honeybees can be used to vector biocontrol agents against plant pathogens and insect pests. That technology, although in its infancy, provides the double benefit of crop pollination and protection (Kevan et al. 2003).

\section{Recommendations}

Honey packers and beekeepers should endorse and promote non-chemical approaches to pest management, within and outside beehives. The benefits are reflected in quality of product, whether produced inside the hive or outside.

The use of honeybees to vector biocontrol agents is not without risk, so recommendations associated with safety and residues (above) apply.

Beekeepers need to be better informed to profit from new possibilities arising from basic and applied research. Tightened relationships with scientists in their regions will allow beekeepers to acquire knowledge that will enable them to adapt more rapidly to emerging opportunities.

\section{Honey production and pollination in new cultivation areas}

As agriculture expands into new cultivation areas, especially in the developing world where natural vegetation is being reduced alarmingly, opportunities for specialty honey production may be being jeopardized (e.g. tropical forest ecosystems). Honeybees may play an exceedingly important role as crop pollinators in situations where forest remnants are not close enough to the crop to be able to provide the services of native pollinators, as it is the case for coffee farms in Costa Rica (Ricketts 2004). On the other hand, in places where agricultural activity is being used to rehabilitate stressed landscapes (e.g. combating desertification) honey bees can be important in sustainability of productivity. Thus, encouragement of beekeeping for production of high quality honeys can be regarded as an important contribution to landscape rehabilitation and conservation.

\section{Recommendations}

Honey packers and beekeepers should endorse and promote broad-minded approaches to considerations of the potential value of their industries to ecosystem management. The benefits will be reflected in quality and diversity of product, pollination, crop production, and overall landscape biodiversity.

\section{Acknowledgments}

This Contribution originated as a report to Honey International Packers Association from The International Network of Expertise for Sustainable Pollination.

\section{Dan Eisikowitch (dane@tauex.tau.ac.il)}

Department of Plant Sciences, The George S. Wise Faculty of Life Sciences, Tel Aviv University, Ramat Aviv, Israel

Peter G. Kevan (pkevan@uoguelph.ca)

International Network of Expertise on Sustainable Pollination (INESP), Department of Environmental Biology, University of Guelph, Guelph, ON NIG 2WI, Canada

Wanja Kinuthia (eafrinet@africaonline.co.ke)

Department of Invertebrate Zoology, national Museums of

Kenya, P. O. Box 40658, 001 00, Nairobi, Kenya

Peter Martin (honeysci@aol.com)

Chairman, Honey International Packers Association (HIPA)

E. C. Mussen (ecmussen@ucdavis.edu) Department of

Entomology, University of California, Davis, CA 956। 6-8584, U.S. A.

Uma Partap (upartap@icimod.org)

Beekeeping Project, ICIMOD, P.O.Box 3226, Kathmandu, Nepal

O. R. Taylor (chip@ku.edu)

Entomology Program, University of Kansas, 1200 Sunnyside

Avenue, Lawrence, KS 66045-7534, U. S. A.

Vernon G, Thomas (vthomas@uoguelph.ca)

Department of Integrative Biology, University of Guelph,

Guelph, ON NIG 2WI, Canada

R.W.Thorp (rwthorp@ucdavis.edu)

Department of Entomology, University of California, Davis, CA 956।6-8584, U. S. A.

Carlos H. Vergara (carlosh.vergara@udlap.mx)

Departamento de Ciencias Químico-Biológicas, Universidad de las Américas, Puebla, 72820 Santa Catarina Mártir, Puebla, México

Kimberly Winter (kw@nappc.org)

North American Pollinator Protection Campaign, 0105 'B' Cole Student Activities Bldg, University of Maryland College Park, MD 20742-I026, U. S. A. 


\section{References}

Belzunces, L P; Pélissier, C; Lewis, G B (eds) (2001). Hazards of pesticides to bees. INRA Editions, Paris. pp.308

Bogdanov, S (2006). Contaminants of bee products. Apidologie 37: I - 18

Borneck, R; Merle, B (1989). Essaie d'une evaluation de l'incidence économique de l'abeille pollinisatrice dans l'agriculture europeénne. Apiacta 24:33 - 38.

Buchmann, S L; Nabhan, G P (1996). The Forgotten Pollinators. Island Press, Washington, DC, USA.

Carreck, N; Williams, I (1998) The economic value of bees in the UK. Bee World 79: $115-123$.

Eisikowitch, D. (200 I). Honeybees and nectariferous plants in the desert are important factor to sustain modern agriculture. In: Pasternak, D; Schlissel A (eds) Combating Desertification with Plants. Kluwer Academic/Plenum Press, New York, NY, USA.

Gordon, j; Davis, L (2003). Valuing Honeybee Pollination. RIRDC, Canberra, Australia. pp. 36

Imdorf, A; Charrière, J D; Kilchenmann, V; Bogdanov, S; Fluri, P. (2003) Alternative strategy in central Europe for the control of Varroa destructor in honey bee colonies. Apiacta 38: 258-278.

Johansen, C A; Mayer, D F (1990). Pollinator Protection: A Bee and Pesticide Handbook. Wicwas Press, Cheshire, CT, USA.

Kevan, P G (2004). IPM × 2: Integrated pest and pollination management (Healthy bees for healthy farming). Memorias de I I? Congreso Internacional de Actualización Apícola, Moterrey, NL. Mexico. pp. 1 I 8 - 122.

Kevan, P G; Al-mazra'awi, M S; Sutton, J C; Tam, L; Boland, G; Broadbent, B; Thomson, S V; Brewer, G J (2003). Using pollinators to deliver biological control agents against crop pests. Pesticide Formulations and Delivery Systems: Meeting the Challenges of the Current Crop Protection Industry. ASTM STP I 430 (Downer, R. A; Mueninghoff, J. C; Volgas, G C (eds)). American Society for Testing and Materials International, West Conshohocken, PA, USA. pp. 148 - 152.

Kevan, P G; Phillips T W (200I). The economic impacts of pollinator declines: An approach to assessing the consequences. Conservation Ecology 5(I): 8 (on-line http://www.consecol.org/vol5/iss I/art8 (19 pp.)

Malone, L A (2004). Potential effects of GM crops on honey bee health. Bee World 85: 29 - 36.

Morse, R A; Calderone N W (2000). The value of honey bees as pollinators of US crops in 2000. Bee Culture 128(3): I - 15.

NRC (National Research Council of the National Academies of the United States of America) (2006). Status of Pollinators in North America. The National Academies Press, Washington, D. C. (in press).

Ohe, von der W. (2003) Control of American foulbrood by using alternative eradication method and artificial swarms. Apiacta 38, 137-139

Partap, U; Partap, T (2002). Warning Signals from Apple Valleys of the Hindu KushHimalayas: Productivity Concerns and Pollination Problems. ICIMOD, Kathmandu, Nepal; pp 124.

Ricketts, T H (2004). Tropical forest fragments enhance pollinator activity in nearby coffee crops. Conservation Biology 18 :1262-1271.

Roubik, D W (2002). Feral African bees augment neotropical coffee yield. In: Pollinating Bees- The Conservation Link Between Agriculture and Nature. Edited by Kevan, P; Imperatriz Fonseca, V.L. Brasilia : Ministry of Environment, pp. 225-266.

Rucker, R R; Thurman, W N; Burgett, M (2003). Internatlizing reciprocal benefits : The economics of honeybee pollination markets. www2.ncsu.edu/unity/lockers/project/ arepublication/Internalization-full.pdf

Schur, A; Wallner, K (1998). Wirkstoffeneintrag durch Sammelbienen nach Applikation von bienenungefährlichen Pflanzenschutzmitteln in blühenden Winterraps. Apidologie $29: 417-419$

Southwick, E E; Southwick, L (1992). Estimating the economic value of honey bees (Hymenoptera: Apidae) as agricultural pollinators in the United States. Journal of Economic Entomology 85: 621 - 633.

Spivak, M; Gilliam, M (1998). Hygeinic behvaiour of honeybees and its application for control of brood diseases and varroa. Bee World 79: 124 - 134

Sumner, D A; Boriss, H (2006). Bee-conomics and the Leap in Pollination Fees. Update. Agriculture and Resource Economics 9:9-11.
Waite, R; Brown, M; Thompson, H; Bew, M (2003) Control of American foulbrood by eradication of infected colonies. Apiacta 38: I34- 136.

Williams, I H (2002a). The EU regulatory framework for GM food in relation to bees. Bee World 83: 24 - 35

Williams, I H (2002b). The EU regulatory framework for GM food in relation to bee products. Bee World 83: $78-87$.

Williams, I H (2002c) Cultivation of GM crops in the EU, farmland biodiversity and bees. Bee World 83: I19-133.

Item A: Literature on GMOs and bee products

http://www.maf.govt.nz/mafnet/rural-nz/research-and-

development/biotechnology/literature-review-gm-plants-and-bee-products/gmplants-bees-08.htm 